Published online 2014 July 27.

Editorial

\title{
Welcome to the First Issue
}

\author{
Mohammad Amouzadeh Khalili ${ }^{1,}{ }^{, *}$ Amir Hoshang Bakhtiary ${ }^{2}$ \\ ${ }^{1}$ Department of Physiotherapy, Faculty of Rehabilitation, Semnan University of Medical Sciences, Semnan, IR Iran \\ ${ }^{2}$ Neuromuscular Rehabilitation Research Center, Semnan University of Medical Sciences, Semnan, IR Iran \\ ${ }^{*}$ Corresponding author: Mohammad Amouzadeh Khalili, Department of Physiotherapy, Faculty of Rehabilitation, Semnan University of Medical Sciences, Semnan, IR Iran. Tel: +98- \\ 9126312621, E-mail:moh35ir@yahoo.co.uk
}

Received: June 27, 2014; Accepted: July 10, 2014

Keywords:Rehabilitation; Health

Welcome to the first issue of The Middle East Journal of Rehabilitation and Health. With the first issue, we launch this new journal as a scholarly, fully refereed, online only publication aimed at promoting the development of rehabilitation and health as a discipline.

This new journal provides a forum for researchers and colleagues to discuss issues related to managing and retrieving clinical and scientific research data on rehabilitation and health. The journal will be published quarterly. In addition to original research papers, the journal will publish case studies, editorials, and reviews.

Hereby we express our thanks to many researches and colleagues for their collaborative effort that helped us to start this journal. We are particularly grateful to the colleagues at the Semnan University of Medical Sciences. We hope that the journal become the main means of sharing and preserving ideas and researches in the field of rehabilitation and heath. 